\title{
Where a male is hard to find: consequences of male rarity in the surfgrass Phyllospadix torreyi
}

\author{
Christine A. Buckel ${ }^{1,4, *}$, Carol Anne Blanchette ${ }^{2}$, Robert R. Warner ${ }^{3}$, \\ Steven D. Gaines ${ }^{3}$ \\ ${ }^{1}$ Interdepartmental Graduate Program in Marine Science, University of California, Santa Barbara, California 93106, USA \\ ${ }^{3}$ Department of Ecology, Evolution, and Marine Biology, University of California, \\ Santa Barbara, California 93106, USA \\ ${ }^{2}$ Marine Science Institute, University of California, Santa Barbara, California 93106, USA \\ ${ }^{4}$ Present address: National Oceanic and Atmospheric Administration, Center for Coastal Fisheries and Habitat Research, \\ 101 Pivers Island Road, Beaufort, North Carolina 28516, USA
}

\begin{abstract}
Determining whether seed production is limited by pollen availability has been an area of intensive study. Past studies have focused largely on terrestrial species with biotic pollination modes, but precise causes and consequences of pollen limitation remain unknown. Here, sex ratio, seed production, seed recruitment, and viability were examined in intertidal populations of a dioecious, abiotically pollinated marine angiosperm, Phyllospadix torreyi (Torrey's surfgrass). Using field surveys and a common garden experiment, this study was conducted near Santa Barbara, California, USA, from 2007 to 2008. Reproduction and recruitment of $P$. torreyi primarily occur near the parental source (tens of meters) because female reproductive success ratio (RSR, measured as the ratio of fertilized ovules to total ovules) increased with local pollen production (RSR range: $0.02-0.71$ ), and seed recruitment was predicted by local (site) seed production and elevation zone within the intertidal. Low RSR at sites with extreme male rarity $(<0.3$ male flowering shoots $\mathrm{m}^{-2}$ ) suggests that pollen limitation is occurring within this system. Seed recruitment was predicted by local (site) seed production and elevation zone (area of potential seed recruitment within the intertidal). The occurrence of seed production and recruitment at sites with extreme male rarity suggests some dispersal of seeds and pollen extending beyond the immediate vicinity of the site. Pollen or seed dispersal over longer distances, although rare, may reduce habitat fragmentation by facilitating colonization of newly available habitat. Localized pollen availability affected seed quantity but not quality; seed germination and growth were uniform among sites.
\end{abstract}

KEY WORDS: Pollen limitation · Sex ratio - Sex bias · Dispersal · Seed viability · Seagrass · Reproductive failure $\cdot$ Dioecy

Resale or republication not permitted without written consent of the publisher

\section{INTRODUCTION}

Fisher's (1930) sex ratio theory argued that for panmictic populations, evolutionary forces should maintain sex ratios at an 'unbeatable' 1:1 ratio as long as male and female offspring were equally costly to produce. It is well documented that Fisher's argument can be invalidated by a number of genetic and be- havioral asymmetries (e.g. Hamilton 1967, Maynard Smith 1978, Frank 1989, Werren \& Beukeboom 1998). Understanding the mechanism(s) producing a non-random sex ratio provides insight to a population's evolutionary history and its structure with regard to competition for mates and resources. Less well understood are the consequences of skewed sex ratios, including low reproductive success or even 
failure, which may provide insight into the stability and cost of sex bias.

Reproductive failure in plants is a result of complications during pollination, fertilization, or fruit or seed maturation. Two factors often cited as influencing plant reproductive success are pollen availability to ovules (reviewed by Ashman et al. 2004, Knight et al. 2005) and resources available for fruit and seed maturation (Stephenson 1992). These factors may work independently or they may jointly contribute to seed production or limitation (e.g. Campbell \& Halama 1993). While resource limitation does occur (Knight et al. 2006), recent meta-analyses and models of seed production indicate that pollen limitation is a common cause of low reproductive success (Burd 1994, 2008, Larson \& Barrett 2000, Ashman et al. 2004, Knight et al. 2005).

Reproductive failure may occur if the pollen received is insufficient, excessive, delayed, or overly mixed in composition (Wilcock \& Neiland 2002), factors that can arise from skewed sex ratios or flowering asynchrony. Pollen limitation may result from an inadequate quantity or quality of pollen received by the stigmas. Deleterious effects from pollen quality occur where self-generated or related pollen disables ovaries by preventing cross-pollination and decreasing seed production (Aizen \& Harder 2007).

Proximity of males and females can greatly influence reproductive success, particularly for obligate outcrossing species such as Phyllospadix torreyi (Torrey's surfgrass). Pollen deposition is a predominantly localized process; pollen vectors typically disperse pollen locally (Harder \& Barrett 1996), and pollen density in anemophilic and hydrophilic plants rapidly decreases with distance from the pollen source (Okubo \& Levin 1989, Ruckelshaus 1996, Ackerman 2002). Reduced pollen reception occurs where plant density is low (Davis et al. 2004, Steven $\&$ Waller 2007) or habitats are fragmented (Cascante et al. 2002, Aguilar \& Galetto 2004). Loss of fecundity due to lack of spatial proximity is further compounded when overall pollen production is low due to male rarity or poor pollen quality; however, there are possible adaptations to alleviate these negative effects. Selection pressure on floral traits, e.g. increased attraction, nectar rewards, or high pollen: ovule ratios, and mating systems, e.g. evolution toward self-compatibility or anemophily (wind pollination), can mitigate limitations of pollen dispersal (reviewed by Knight et al. 2005). For example, Burd's (1995) ovule packaging model proposes the evolutionary adaptation of producing excess ovules per flower where pollen receipt is unpredictable, as a form of bet hedging. Here, the fitness benefits of ovule overproduction are greatest where stigmatic pollen loads are variable and the costs of ovules are low (Burd 1995). Documentation of pollen limitation and low reproductive success in dioecious plants with abiotic pollination is rare, and is often investigated using species in areas of fragmented habitats or low plant density (e.g. Steven \& Waller 2007). Among plants with abiotic pollination, nearly all reports address anemophilous plants. How aquatic plants adjust to pollen-limited conditions is an area that has received little attention to date; to our knowledge, only a few studies have examined the causes and consequences of reproductive failure in dioecious hydrophilous, or water-pollinated, plants (Shelton 2008, 2010c, Van Tussenbroek et al. 2010).

Marine angiosperms, or seagrasses, are a polyphyletic group in which dioecy is the most common mating system, expressed in $78 \%$ of species and 9 of 13 genera (Pettitt et al. 1981). They are highly specialized plants with uniquely evolved functional morphologies such as reduced flowers that facilitate submarine pollination (Ackerman 2006). While such adaptations promote pollination and fertilization, reproductive success and outcrossing rates in hydrophilic plants are also influenced by physical factors (depth and currents; Ackerman 2000) and density of flowering shoots (Reusch 2003, Van Tussenbroek et al. 2010). Reproductive success of some dioecious seagrass species, measured as fraction of fertilized ovules, is well below the potential maximum of 1.0 (Shelton 2008, Van Tussenbroek et al. 2010). Much of seagrass reproduction is clonal, yet sexual reproduction appears to be important based on evidence of high outcrossing rates for a variety of seagrass species (Reusch 2000, Waycott et al. 2006). For seagrasses, few studies have examined the influence of unequal sex ratios on seed production. Most populations of Phyllospadix spp. are female-biased (see below), but seed production estimates range widely, from nearly $100 \%$ successful (Williams 1995, Reed et al. 2009) to nearly $100 \%$ failed (Shelton 2008).

Phyllospadix torreyi, an important foundation species of the rocky intertidal (Shelton 2010a) from Baja California (Mexico) to Canada (Phillips 1979), is dioecious and produces sexually dimorphic flowers within spadices. Flowering shoots contain multiple spadices, typically 5 , housing many uniovulate flowers or anther pairs (den Hartog 1970, Williams 1995). With single-seeded fruits, measurements of fruit and seed production are equivalent; in this paper we refer only to seed production. Flowering buds are 
formed in late spring, and pollination extends from early summer to early fall (Reed et al. 2009). The range of pollen transport is unknown for $P$. torreyi; in other seagrass species with filiform pollen it is on the order of tens of meters or less (Ruckelshaus 1996, Verduin et al. 1996, Ackerman 2002). Fruit development typically occurs throughout the summer, with full maturation requiring $\sim 3 \mathrm{mo}$; peak seed dispersal is completed by mid-fall (Reed et al. 2009). P. torreyi and its congeners are found along rocky shorelines of the northern Pacific Ocean. Phyllospadix spp., unlike most seagrasses which are found in comparatively calm water estuaries or embayments, are exposed to turbulent, high wave energies which may influence the scale of pollen and seed dispersal. For another open-coast plant, the giant kelp Macrocystis pyrifera, Gaylord et al. (2006) found that turbulence and wave-driven processes were important to localized spore transport.

Female-biased sex ratios have been documented for the genus Phyllospadix (Williams 1995, Shelton 2008, 2010b,c), and recent work has shown that sex ratios can vary among spatially segregated populations (Addison 2009, Reed et al. 2009). A variety of mechanisms may produce skewed sex ratios of flowering shoots, including spatial segregation of the sexes, non-random production of gender, or differential mortality or growth. Sex determination mechanisms in Phyllospadix are unknown (Shelton 2010c), but chromosomal rather than environmental determination has been suggested (Stewart \& Rudenberg 1980). Recent evidence suggests that spatial segregation of sexes is not occurring in this region (Addison 2009), contrary to previous reports (Williams 1995). Genetic analyses of congener seedlings found seedling sex ratios near 0.5 , changing to female bias with increasing clone age (Shelton 2010c). Differential growth (Williams 1995) or mortality (Shelton 2008, 2010b,c) may produce the observed skewed sex ratio. A demographic model of the congeners $P$. scouleri and $P$. serrulatus identified small sex differences in mortality over the lifespan of a genet, and some survival-reproduction trade-offs can generate stable but skewed sex ratios (Shelton 2010b), resulting in a female bias near observed levels.

The variation in Phyllospadix torreyi sex ratio prompted us to examine how its sex ratios, and male rarity in particular, may influence seed production, seedling quality, and recruitment success. We identified the sex ratios of $P$. torreyi at a number of sites and hypothesized that seed production will be low where male flowering shoots are rare. We further hypothesized that reduced seed production should result in low recruitment success. Since seed production appears to occur on a localized scale (i.e. within a site; see our Results below and similar findings in congeners, Shelton 2008), we hypothesized that male rarity would result in lower quality fruits (potential mechanisms include lower pollen competition and reduced genetic diversity) relative to populations with sex ratios closer to 1:1. We examined differences in germination and growth of seeds produced at our study sites to determine whether density of male flowering shoots influenced seed quality.

\section{MATERIALS AND METHODS}

\section{Study area and sampling design}

This study was conducted between June 2007 and February 2008 along the east-west trending coastline of Santa Barbara County, California, USA (Fig. 1). The region consists of a rocky intertidal environment, with some areas having boulder fields as opposed to continuous rocky shore. We established survey areas at 7 sites spanning a $50 \mathrm{~km}$ section of the coast (Fig. 1): Coal Oil Point (COP), Devereux (DEV), Hendry's Beach (HD), Miramar (MM), Loon Point (LP), Toro Canyon (TC), and Carpinteria Beach (CB). Survey areas extended $30 \mathrm{~m}$ alongshore, beginning at the shallowest edge of perennial surfgrass distribution, with variable cross-shore distances due to differences in slope (Table 1). Survey areas were delineated with permanent markers as well as GPS coordinates, allowing an accurate location of the area at each sampling interval.

\section{Sex ratio surveys}

Sex ratios were determined for each site in summer 2007 (June to August) during periods of peak flowering. Within each survey area, a grid of $1 \mathrm{~m}^{2}$ cells was constructed using transect tapes. We placed $1 \mathrm{~m}^{2}$ quadrats throughout the survey area at randomly selected grid locations and counted the number of male and female flowering shoots (FS) per quadrat (n quadrats per site: $\mathrm{COP}=133, \mathrm{DEV}=116, \mathrm{HD}=125$, $\mathrm{MM}=15, \mathrm{LP}=24, \mathrm{TC}=17, \mathrm{CB}=83$ ). Flower development was synchronized, with anther release occurring while stigmas were exposed and receptive, enabling visual differentiation of male and female spadices in the field. Two estimates of local pollen production were measured: density of male FS (no. $\mathrm{m}^{-2}$ ) and sex ratio; direct pollen counts were not 


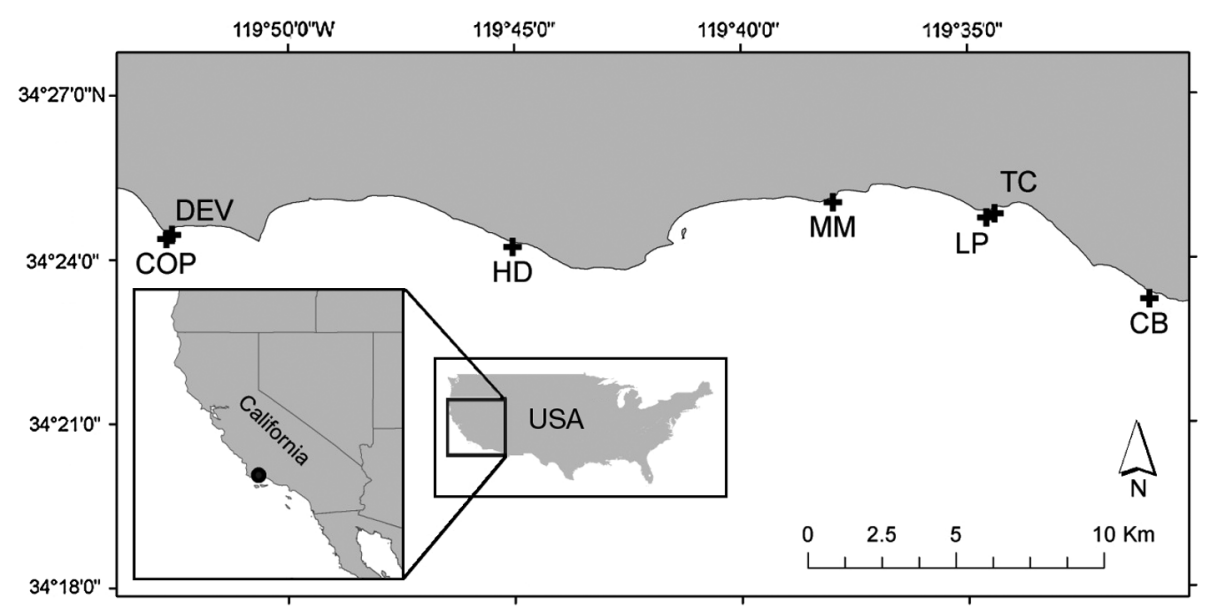

Fig. 1. Surveyed sites along Santa Barbara County (California, USA) coastline (• on inset map) from 2007 to 2008. Site codes: COP, Coal Oil Point; DEV, Devereux; HD, Hendry's Beach; MM, Miramar; LP, Loon Point; TC, Toro Canyon; CB, Carpinteria Beach
Table 1. Phyllospadix torreyi male and female flowering shoot (FS) densities (mean $\pm \mathrm{SE}$ ), sex ratios, and survey area across sites (alongshore $x$ cross-shore). Sex ratios were tested against a null expectation of 0.5 using a binomial test (among-site differences; $G=1027.36, \mathrm{p}<0.0001$, $\mathrm{df}=6$ ). ns: not significant, ${ }^{*} \mathrm{p}<0.05,{ }^{* *} \mathrm{p}<0.01$. Site codes as in Fig. 1

\begin{tabular}{|lrrll|}
\hline Site & \multicolumn{2}{c}{ FS density $\begin{array}{c}\left(\text { no. } \mathrm{m}^{-2}\right) \\
\text { Male }\end{array}$} & \multicolumn{1}{c|}{$\begin{array}{c}\text { Sex ratio } \\
\text { Female }\end{array}$} & $\begin{array}{c}\text { Survey area } \\
(\mathrm{m} \times \mathrm{m})\end{array}$ \\
\hline COP & $0.03 \pm 0.02$ & $1.90 \pm 0.48$ & $0.02^{* *}$ & $30 \times 20$ \\
DEV & $0.36 \pm 0.26$ & $7.65 \pm 1.52$ & $0.05^{* *}$ & $30 \times 25$ \\
HD & $0.97 \pm 0.35$ & $1.62 \pm 0.28$ & $0.37^{* *}$ & $30 \times 21$ \\
MM & $15.80 \pm 8.00$ & $16.30 \pm 5.35$ & $0.49 \mathrm{~ns}$ & $30 \times 4$ \\
LP & $8.58 \pm 3.49$ & $12.60 \pm 5.32$ & $0.41^{* *}$ & $30 \times 4$ \\
TC & $15.20 \pm 5.63$ & $18.40 \pm 7.01$ & $0.45^{*}$ & $30 \times 4$ \\
CB & $0.00 \pm 0.00$ & $6.37 \pm 1.75$ & $0.00^{* *}$ & $30 \times 29$ \\
Mean & $5.84 \pm 2.74$ & $9.26 \pm 2.52$ & $0.25 \pm 0.08$ & \\
& & & & \\
\hline
\end{tabular}

ratio (0.5) using a binomial test (JMP 8.0, SAS Institute 2009).

\section{Reproductive investment and success}

We collected a minimum of 20 female FS from each site in October 2007, at the end of the fruit-ripening period but prior to mature seed dehiscence (n female FS: $\mathrm{COP}=31, \mathrm{DEV}=31, \mathrm{HD}=32, \mathrm{MM}=32$, $\mathrm{LP}=34, \mathrm{TC}=40, \mathrm{CB}=23$ ). Each spadix was examined under a dissecting scope, and all fruits and ovules were counted and assigned a developmental stage. Ovules were classified using 3 general categories: viable, grazed, and non-viable. Non-

completed. Within the intertidal, the number of spadices per flowering shoot and pollen production per male flower was found to be relatively consistent in Phyllospadix torreyi elsewhere in California (Williams 1995) and was assumed to be uniform within and among study sites. Sex ratios were calculated as the proportion of male FS to total (sum of male and female) FS. While male density and sex ratio can be correlated, the 2 measures are related to absolute and relative pollen availability, respectively. Sex ratios were calculated using FS densities because estimates of sex ratios of individual genets are impossible for surfgrass without using genetic analysis, due to clonal growth (Shelton 2008, 2010c). Genetic analysis of the congeners $P$. scouleri and $P$. serrulatus showed that non-flowering males were rare (Shelton 2010c), suggesting that flowering sex ratios reflect individual sex ratios in surfgrass. A Gtest of independence was used to examine amongsite differences in sex ratio; the sex ratio at each site was tested against a null expectation of an even sex viable ovules included aborted (or halted) ovules. Aborted ovules remained small in size ( $3 \mathrm{~mm}$ width $\times$ $1 \mathrm{~mm}$ depth, $0.007 \mathrm{~g}$ ) throughout development, and at advanced stages were uniformly brown-black and collapsed under light pressure. Viable ovules were initially identical in size to non-viable ovules but within a month after fertilization became large and swollen $(4 \mathrm{~mm}$ width $\times 2 \mathrm{~mm}$ depth, $0.02 \mathrm{~g}$ ). Mature fruits were taut and changed from uniformly green, to mottled green-brown, to brown-red just prior to dehiscence of fruits (hereafter referred to as seeds). Grazed fruits had extensive damage by herbivores (as described by Holbrook et al. 2000). For this analysis, grazed fruits were included with viable ovules to quantify reproductive success; however, they were ultimately not viable due to endocarp damage. At each site, we measured female reproductive investment (RI) as the total ovule production per FS (sum of viable seeds, grazed fruits, and non-viable ovules) and the reproductive success ratio (RSR) per FS as the ratio of the total fertilized ovules (sum of viable 
and grazed) to total ovules, and asked whether variation in proxies for pollen production (i.e. density of males or sex ratio) explained the measures of RI and RSR at each site.

RI and success ratios (RSR) of female FS were compared among sites using a 1-way analysis of variance (ANOVA; JMP 8.0, SAS Institute 2009). Model residuals were examined for normality using quantile plots. To address non-normality, an arcsine squareroot transformation was applied to the RSRs, and a square-root transformation was used for RI. Post hoc contrast tests were performed for RI and RSR for all sites. For between-site comparisons, a sequential Bonferroni correction was applied to results from Student's $t$-tests to control group-wide Type I error rates (Rice 1989). We used pairwise correlations (Pearson and Spearman's) to evaluate the relationship between pollen production and reproductive success.

Because of the near complete lack of seed production at CB in 2007, a small experiment was completed in 2008 at CB to evaluate whether female flowering shoots from there were capable of producing fruit when supplemented with pollen. In June 2008, 4 male flowering shoots with anthers partially dehisced were collected from MM. One anther per FS was released into $\sim 500 \mathrm{ml}$ of seawater and agitated. At $\mathrm{CB}, 15$ female FS with spadices containing flowers ready to be pollinated (stigmas recently exposed, erect, and not wilted) were marked using bird bands and survey grid coordinates (along shore, crossshore distance). Dialysis tubing, which allows water diffusion but retains higher molecular weight compounds (i.e. pollen) within the tube, was cut into sections longer than the spadix length (about $10 \mathrm{~cm}$ ), knotted at 1 end, and filled with pollen-seawater mixture $(\sim 20 \mathrm{ml})$. The target spadix was placed in the tubing; the tubing was secured to the base of the spadix with waterproof tape. The pollen-filled tubes were removed after $24 \mathrm{~h}$. In September, the treated spadices were recovered and examined for evidence of fruit development.

\section{Seed recruitment}

To determine whether seed recruitment of Phyllospadix torreyi occurred on a geographically closed (within site) or open (between site) scale, we examined the relationship between seed production and recruitment at the study sites. Surfgrass seed recruitment was measured as the density of seedlings. Surfgrass seeds have a dormancy period of $6 \mathrm{wk}$ (Kuo et al. 1990), so seedlings observed in winter were most likely released as seeds during the previous summer. We surveyed seed recruitment at all sites in February 2008. The seedling survey area encompassed the survey grid used at each site and the area shoreward of the grid that was within the realm of potential seed dispersal. Seed recruits were counted in randomly placed $0.09 \mathrm{~m}^{2}$ quadrats within 3 elevation zones (n quadrats per site: $\mathrm{COP}=64, \mathrm{DEV}=64, \mathrm{HD}=64$, $\mathrm{MM}=49, \mathrm{LP}=30, \mathrm{TC}=29, \mathrm{CB}=68$ ). We designated the elevation zones relative to the existing surfgrass beds at each site: high ( $>2 \mathrm{~m}$ above perennial surfgrass distribution), middle ( $\pm 2 \mathrm{~m}$ from highest edge of perennial surfgrass distribution), and low (>2 m below perennial surfgrass distribution, extending to lowest accessible point). Surfgrass seeds are known to recruit to 'host' plants with branches capable of trapping seeds (i.e. surfgrass or algae, Turner 1983, Blanchette et al. 1999). For each seedling encountered, we identified the host species and visually estimated the percent cover of recruitment habitat, defined as basal area occupied by each individual potential host found within the quadrat. Distinguishing between seedling species was not necessary because all study sites were monospecific $P$. torreyi beds.

We predicted seed recruitment density using a forward step-wise variable selection procedure using the 'step' function in $\mathrm{R}$ software (R Development Core Team 2011). Independent variables included elevation zone, mean seed production (no. $\mathrm{m}^{-2}$ ) from the previous summer at each site, percent cover of recruitment habitat (all host species combined), and all possible interactions. Only seed production, elevation, and the interaction of production and elevation contributed to the final model. Seed production per unit area was calculated for each site using the product of the mean viable seed production per flowering shoot and mean female flower densities. Seed production and seed recruitment density were log transformed to meet model assumptions.

\section{Seed germination success}

A seed germination trial was conducted to evaluate the possible consequences of reduced pollen competition to seed quality and germination, using a common garden experiment. We used seeds produced at sites spanning a range of sex ratios to examine whether germination success and seedling growth varied among sites and whether pollen production explained the variability in germination and vigor. 
A minimum of 20 fruiting shoots per study site were randomly collected in October 2007. Mature seeds were readily removed following gentle pressure applied to the spadix as described by Reed et al. (1998). Over 75 mature seeds were collected from each site (excluding $\mathrm{CB}$ and COP due to a lack of mature seeds), placed in discrete containers, and randomly distributed within a flow-through seawater tank system (n seeds per site: $\mathrm{COP}=6, \mathrm{DEV}=100$, $\mathrm{HD}=100, \mathrm{MM}=136, \mathrm{LP}=78, \mathrm{TC}=106, \mathrm{CB}=2$ ). Tank conditions were maintained at salinity of $30 \mathrm{ppt}$ and water temperature of $15^{\circ} \mathrm{C}$, with a $14: 10 \mathrm{~h}$ light:dark cycle, representing natural conditions in the Santa Barbara region (Reed et al. 1998). Ambient greenhouse light was supplemented with a full spectrum fluorescent light to match the natural light:dark cycle. Seed germination was monitored daily for $32 \mathrm{~d}$ post-dehiscence. Daily counts of germinated seeds, or germlings, allowed for calculation of total days of growth for each individual seedling. At the conclusion of the germination trial, all seeds and germlings were counted, and total leaf production $\left(\mathrm{mm}^{2}\right.$; length $\times$ width of all leaves per germling) was measured with digital calipers to quantify germling vigor.

We compared the fraction of germinated seeds among sites using a chi-squared contingency test (JMP 8.0, SAS Institute 2009). Vigor of the germling, measured as leaf production $\left(\mathrm{mm}^{2}\right)$, was predicted using a forward stepwise selection in R software ( $R$ Development Core Team 2011) as a function of total days of growth, site, and male FS density. Total days of growth and leaf area production were log transformed. Total days of growth was the only contributing factor in the final model.

\section{RESULTS}

\section{Sex ratio surveys}

Female and male FS were found at all sites with the exception of $\mathrm{CB}$, where only females were found. Generally, female FS occurred at higher densities than male FS, ranging from 1.9 to 18.4 females $\mathrm{m}^{-2}$ and 0 to 15.8 males $\mathrm{m}^{-2}$ (Table 1). Male FS were less abundant than female FS at all sites, and sex ratios among sites were significantly different $(G=1027.36$, $\mathrm{p}<0.0001$, $\mathrm{df}=6$ ). The mean sex ratio among sites was 0.25 , with a significant deviation from equal fractions of male and female FS (sex ratio $=0.5$ ) found at all sites but MM (Table 1). Sites LP and TC were less biased towards females than the remaining 4 sites (COP, DEV, CB, and HD).

\section{Reproductive investment and success}

Across sites, female FS had an average of 5 spadices $\mathrm{FS}^{-1}, 11.3$ ovules spadix ${ }^{-1}$, and a mean RI of 56.5 ovules $\mathrm{FS}^{-1}$ (range: 44-72). Comparisons of RI identified significant differences among sites (Fig. 2A, Table 2). Fruit herbivory was low (range: $0.4-1.4 \%$ of ovules) compared to non-viable ovules (range: 27-97.4\% of ovules) at all sites.

At all sites, the RSR was significantly lower than the maximum of 1.0 (Fig. 2B). RSR varied significantly among sites, ranging from 0.02 to 0.707 with a mean of 0.219 for all sites combined (Fig. 2B, Table 2). The 2 sites (CB and COP) with the lowest measures of pollen production (male FS density and sex ratio) had significantly lower RSR than all other
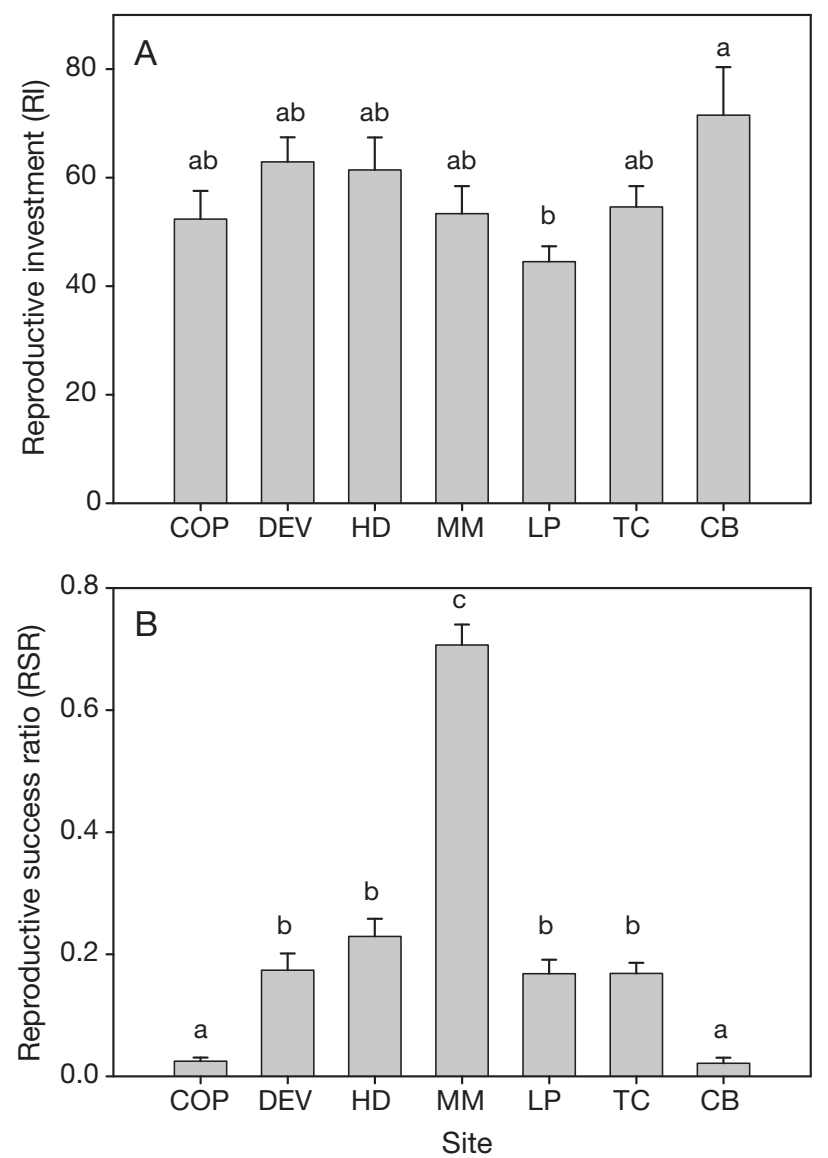

Fig. 2. Phyllospadix torreyi. (A) Mean $( \pm \mathrm{SE})$ reproductive investment, i.e. total ovules per flowering shoot, and (B) reproductive success ratio, i.e. fertilized ovules:total ovules, across the study sites in 2007 in Santa Barbara County, California, USA. Like letters indicate no significant difference between mean values as determined by Students $t$-tests for individual comparisons with subsequent $\mathrm{p}$-value adjustment using sequential Bonferroni analysis (Rice 1989). Site codes as in Fig. 1 
Table 2. One-way analysis of variance (ANOVA) for Phyllospadix torreyi reproductive investment (RI) and reproductive success ratio (RSR) at all sites in 2007

\begin{tabular}{|lccccc|}
\hline \multicolumn{1}{|c}{ Source } & df & SSE & MSE & F-ratio & $p$ \\
\hline RI & & & & & \\
Sites & 6 & 13092.42 & 2182.07 & 2.67 & 0.0162 \\
Residual & 216 & 176746.83 & 818.27 & & \\
RSR & & & & & \\
Sites & 6 & 9.93 & 1.65 & 94.57 & $<0.001$ \\
Residual & 216 & 3.78 & 0.02 & & \\
\hline
\end{tabular}

sites (Fig. 2B). The site with the highest measures of local pollen production (MM) had a significantly higher RSR than all other sites (Fig. 2B).

Much of the RSR variability among sites was explained by local pollen production (Fig. 3). We found significant positive relationships between RSR and the measures of local pollen production (Fig. 3; identical conclusions emerge with Spearman's rank test, conducted on untransformed individual FS data; sex ratio: $\rho=0.681, p<0.001$; male FS density: $\rho=$ $0.681, \mathrm{p}<0.001)$. Sites with extremely low sex ratios (CB and COP) and extremely low densities of male FS had the lowest RSR, while the site with the highest sex ratio and male FS density (MM) had the highest RSR. Values of RSR for all other sites with intermediate levels of pollen production fell between these limits, but not in a linear manner. Removing the site with the highest RSR (MM), the relationships between RSR and pollen production metrics remained highly significant (Pearson correlation, con- ducted on transformed individual FS data; sex ratio: $r=0.483, p<0.001$; male FS density: $r=0.274$, $\mathrm{p}=0.001)$.

Only 2 spadices were recovered from the pollen supplementation experiment. Although our spadix recovery was low, the technique was successful. The treatment spadices had already released their fruits but the scars on the spadix were indicative of successful fruit development and release. Each treatment spadix had 8 ovules which were presumed to have developed into mature fruits (RSR per spadix = 0.88 and 0.73 ) with few non-viable ovules ( $\mathrm{n}=3$ and 1 per spadix). A lower percentage of non-viable ovules was found in 2008 under pollen-supplemented conditions (mean 19\%) than in 2007 under ambient conditions (mean $97.4 \%$ ).

\section{Seed recruitment}

Phyllospadix torreyi seedlings were found attached to a variety of host flora within all elevation zones and sites during the February 2008 surveys. Three species, Chondracanthus canaliculatus, Gracilaria sp., and Corallina sp. comprised over $69 \%$ of the habitat cover and were hosts to over $86 \%$ of the total seedlings counted. Densities ranged from 3 to 24 seedlings $\mathrm{m}^{-2}$, with a mean across-site density of 15.2 seedlings $\mathrm{m}^{-2}$.

We found both seed production and distribution across tidal elevation to be significantly correlated with recruitment (Table 3). Seed recruitment was greatest within the high elevation zone and lowest in
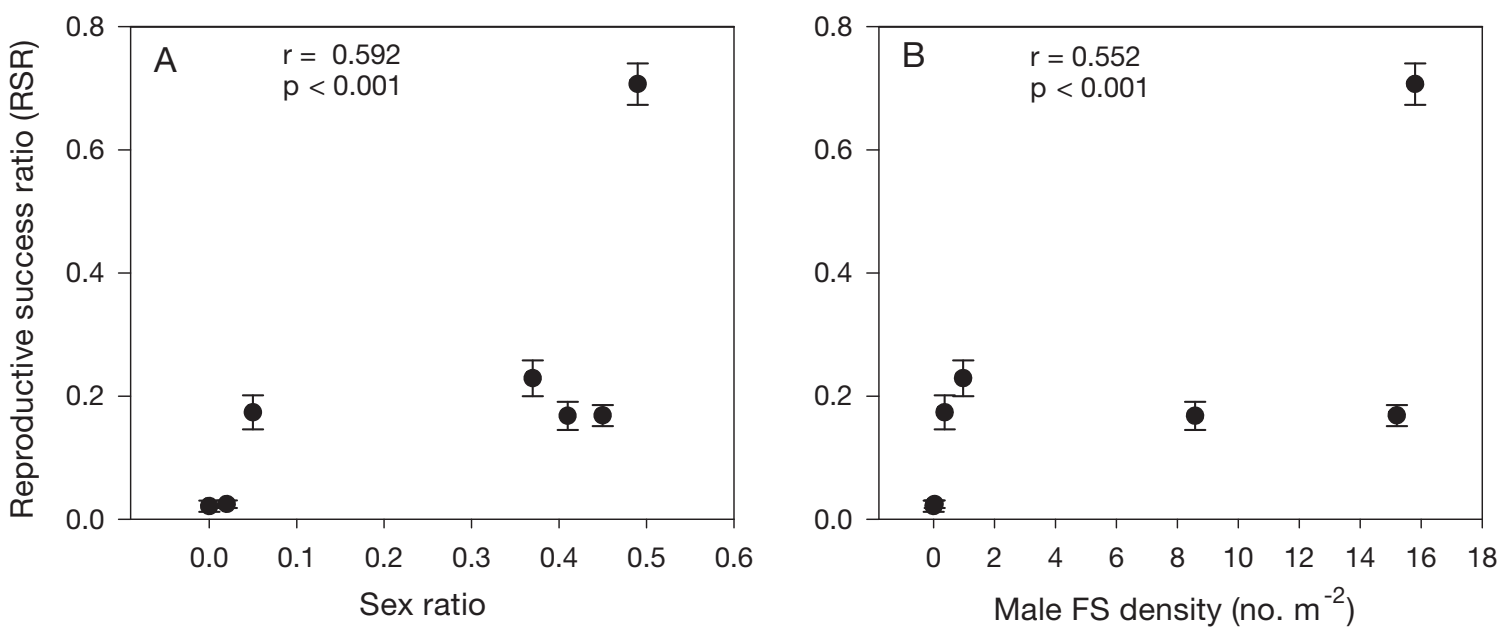

Fig. 3. Phyllospadix torreyi. Reproductive success ratio, i.e. fertilized ovules:total ovules, as a function of (A) sex ratio and (B) male flowering shoot density in 2007. Statistics conducted on arcsine square-root transformed individual flowering shoot (FS) data; back-transformed site means $( \pm \mathrm{SE})$ are shown 
Table 3. General linear model results of Phyllospadix torreyi seed recruitment (no. $\mathrm{m}^{-2}$ ) as a function of elevation and mean seed production within the survey area (see 'Materials and methods'). Independent variables were selected using forward stepwise analysis from the following list: elevation, production, cover, and all possible interactions. Seed production was based on fruiting density in the previous summer

\begin{tabular}{|lcrrr|}
\hline Source & df & SS & F-ratio & $p$ \\
\hline Elevation & 2 & 62.28 & 14.29 & $<0.0001$ \\
Production & 1 & 139.74 & 64.15 & $<0.0001$ \\
Elevation $\times$ Production & 2 & 18.37 & 4.21 & 0.0155 \\
Error & 362 & 788.56 & & \\
\hline
\end{tabular}

the low zone. Mean seed recruitment at a site was positively related to seed production from the previous summer, with the lowest recruitment at sites of lowest production (CB, COP, DEV) and highest recruitment at the site of highest production (MM). At all elevations, seed recruitment increased as seed production increased, but the rate of increase was less at high elevations (Fig. 4). Although seedlings depend on a facilitative host to successfully establish, available recruitment habitat was not a significant predictor of seedling recruitment.

\section{Seed germination success}

Phyllospadix torreyi seeds successfully germinated in the lab without seed scarification or a

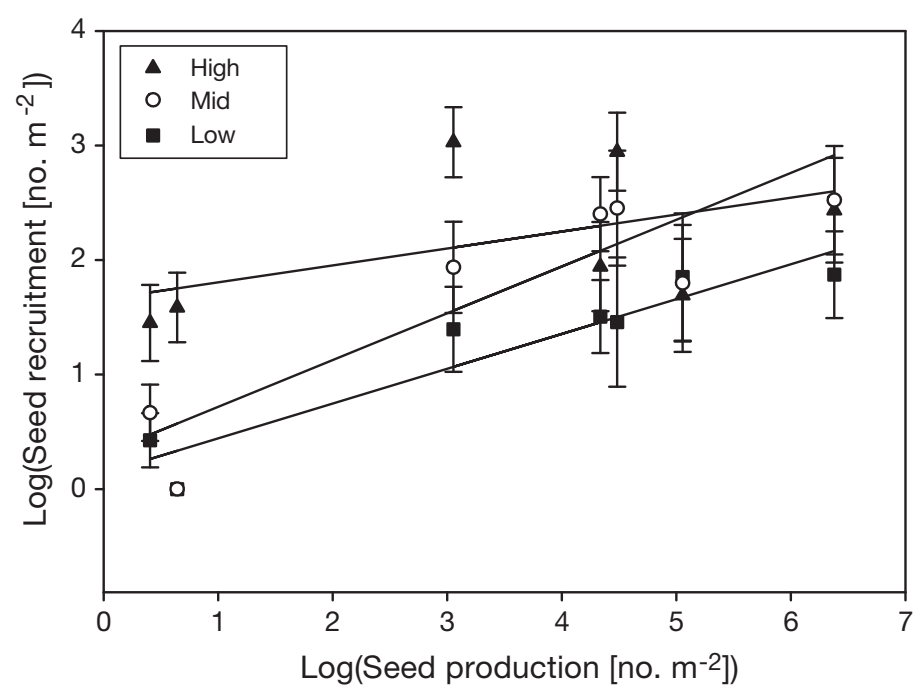

Fig. 4. Phyllospadix torreyi. Mean observed seedling recruitment (no. seeds $\mathrm{m}^{-2} \pm \mathrm{SE}$ ) as a function of elevation zone and mean site seed production in 2008 in Santa Barbara County, California, USA. Linear model predictions of seedling recruitment are plotted for low, mid-, and high elevations

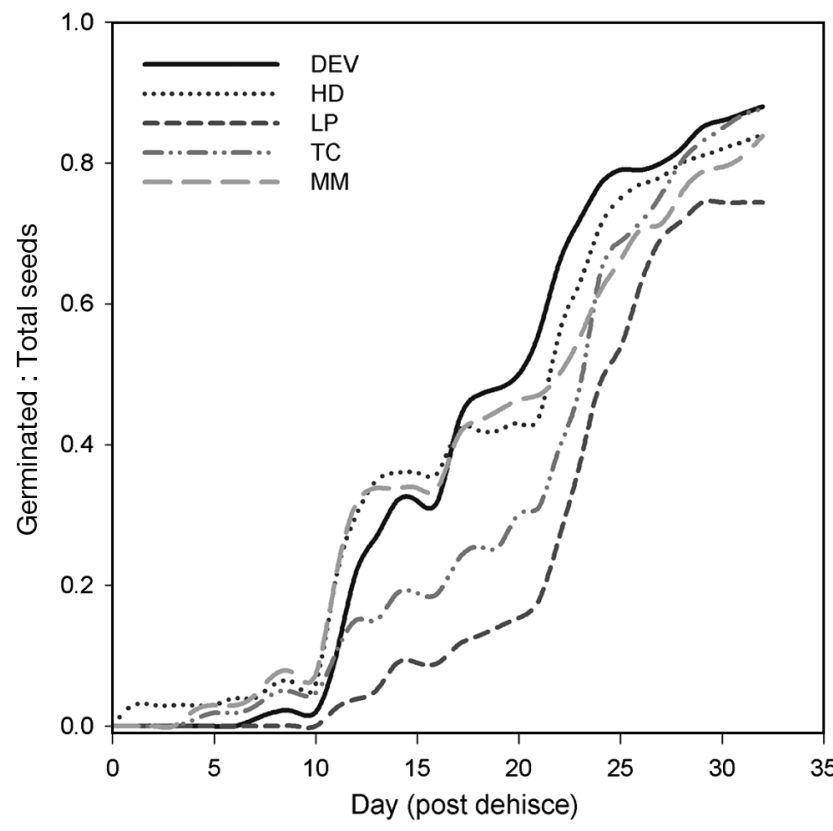

Fig. 5. Phyllospadix torreyi. Fraction of germinated surfgrass seeds as a function of the number of days since dehiscence at 5 collection sites in 2007 in Santa Barbara County, California, USA. Site codes as in Fig. 1

period of dark adaptation. We found high rates of seed germination (mean of $83 \%$ ) occurring in equal fractions among sites ( $\mathrm{n}=520$, df $=4$, Pearson's correlation $\left.\chi^{2}=6.54, p=0.1626\right)$. All sites demonstrated approximately $1 \mathrm{wk}$ of dormancy prior to initiation of germination (Fig. 5). Rate of germination varied among sites, with the most rapid germination occurring at DEV and slowest overall germination at LP. All seedlings continued to grow throughout the experiment, and no post-germination mortality was observed. In the common garden experiment, we found no significant differences in growth among seedlings collected at the various sites. Total days of growth explained the majority of variation of leaf production (Table 4; F-ratio $=2258.6, \mathrm{p}<0.001$ ); all other factors and their interactions (site and male density) did not contribute to the final model. Thus, under optimal growing conditions, we found no effect on seed germination or leaf area when a seed was fertilized under varied conditions of pollen production.

\section{DISCUSSION}

We found evidence of pollen limitation in Phyllospadix torreyi. Sites with extremely low 
Table 4. General linear model results of total leaf Phyllospadix torreyi production $\left(\mathrm{mm}^{2}\right)$ as a function of total days of growth. Independent variables were selected using forward stepwise analysis from the following list: total days of growth, male flowering shoot density, site, and all possible interactions

\begin{tabular}{|lcccc|}
\hline Source & df & SS & F-ratio & $p$ \\
\hline $\begin{array}{l}\text { Days of growth } \\
\text { Error }\end{array}$ & 1 & $\begin{array}{c}482.11 \\
931\end{array}$ & 2258.6 & $<0.001$ \\
\hline
\end{tabular}

male density had low seed production, suggestive of inadequate pollen deposition. This is often the cause of low seed production rates in terrestrial perennial plants (see reviews by Burd 1994, Ashman et al. 2004, Knight et al. 2005), and supports the idea that surfgrass pollination occurred over a limited spatial scale. Across the geographic extent of this study, $P$. torreyi female reproductive success appeared limited more by pollen than by maternal resource provisioning. Recent reviews of terrestrial plants have also provided evidence for pollen limitation (Burd 1994, Larson \& Barrett. 2000, Knight et al. 2005), challenging the long-standing paradigm of resource limitation as driving female reproductive success in plants (Lee \& Bazzaz 1982, Campbell \& Halama 1993).

Our estimates of RSR were low, with some sites producing no fertilized ovules. The range of RSR recorded here is comparable to those of 2 congeners, Phyllospadix serrulatus and P. scouleri (Cox et al. 1992, Shelton 2008), but less than those for P. torreyi at another location in California (Williams 1995). Despite a low RSR, it is important to consider reproductive success (i.e. seed production, establishment, and survival) over the entire lifespan of a genet. As long-lived, clonal perennials, surfgrasses have the ability to reproduce sexually and asexually (vegetative propagation). There is no evidence for apomixis here or in other surfgrasses (Cox et al. 1992, Williams 1995, Shelton 2008). It is likely that both sexual and asexual reproduction are important for surfgrass bed maintenance, improving both shortand long-term population stability (see Ackerman 2006 for summary), but genetic recombination can only be achieved with sexual reproduction. Although attached rhizomes can be fragmented and live (Shelton 2010b), it is not known whether vegetative fragments can reestablish once dislodged, so it is broadly suspected that seed and pollen transport are the only way gene flow occurs over long distances.

While we found a significant relationship between local pollen production and RSR, this relationship was not linear. The extremely low RSRs observed at sites where males were rare suggest that a minimum threshold density of male flowering shoots ( 0.3 male FS $\mathrm{m}^{-2}$ ) may be needed for successful fertilization. To the extent that sexual reproduction contributes to population growth, this is suggestive of a pollenlimited Allee effect (Ashman et al. 2004), as has been observed in other abiotically pollinated species (Davis et al. 2004, Steven \& Waller 2007). The role of sexual reproduction in surfgrass population maintenance and growth has not been quantified. It is likely similar to other long-lived seagrass species, where sexual reproduction contributes to both short- and long-term population persistence (Ackerman 2006). Although the pollen load required for fertilization in Phyllospadix torreyi is unknown, it has one of the largest pollen:ovule ratios among plants $\left(1.8 \times 10^{4}\right.$ to $2.5 \times 10^{4}: 1$; Williams 1995). For comparison, Van Tussenbroek et al. (2010) found that $6.7 \times 10^{4}$ pollen per ovule were required for optimal fertilization of the dioecious aquatic angiosperm Thalassia testudinum. Also, 1000 to 10000 pollen grains were needed to fertilize 1 Zostera marina ovule (Ackerman 2002). However, Z. marina is monoecious and capable of self-fertilization, and pollen densities needed to fertilize an ovule for the dioecious $P$. torreyi may be much greater. Intermediate measures of pollen production (male FS density and sex ratio) increased RSR to near the mean at sites where male densities exceeded $0.36 \mathrm{FS} \mathrm{m}^{-2}$. Similar RSR among sites with a range of male densities suggests that other mechanisms may be controlling fertilization success once some threshold of pollen density is achieved.

In this study, male density explained $\sim 40 \%$ of the variability in RSR. Other possible explanatory factors include spatial isolation of flowering shoots (Reusch 2003), seed predation (Holbrook et al. 2000), flowering asynchrony (Post et al. 2001), maternal resource provisioning (Zimmerman \& Pyke 1988), and poor pollen quality (Aizen \& Harder 2007). Relatively little grazing or predation was observed $(<2 \%$ of all ovules) in this study. Asynchronous flowering is an unlikely cause of reproductive failure because we observed males in anthesis when female stigmas were exposed. Although the pollen supplementation experiment was small and lacked controls, the data are suggestive that maternal resources appear not to be limiting. Further study is needed to conclusively rule out resource limitation as a contributing factor to reproductive failure here; elsewhere for congeners, the production of surfgrass reproductive structures has been suggested to be not very costly (Shelton 2010c). Additionally, pollen quality complications 
may have occurred and include incompatibility of pollen and ovule genotypes, mutation load, and pollen-style interactions (Ackerman 1993, Aizen \& Harder 2007). Although we cannot conclusively identify pollen quality or pollen receipt as the cause of low reproductive success, the pollen production data strongly suggest the latter. The low RSRs observed may partly be a result of variability in RI, as evidenced by the large number of ovules at the site of lowest male density. Although testing for evidence of bet hedging was beyond the scope of this study, the among-site variability we observed in total ovule production merits further investigation.

The decreasing RSR with increasing distance from a pollen source documented for two Phyllospadix torreyi congeners ( $P$. souleri and $P$. serrulatus) is consistent with the pattern expected when pollen is retained within the area of release (Shelton 2008). It is likely that pollen do not disperse widely because of the dampening of water flow velocity and turbulence within the surfgrass canopy. Although flow within surfgrass meadows has not been quantified, a nearly universal dampening of flow within seagrass canopies has been documented (Fonseca et al. 1982, Verduin \& Backhaus 2000) with an exponential decline in pollen availability as a function of distance from male flowers (Ruckelshaus 1996, Ackerman 2002). Thus the majority of pollen is expected to be retained locally, with some long-distance dispersal predicted based on the leptokurtic shape of the dispersal probability distribution. No males were observed at $\mathrm{CB}$, yet 9 maturing fruits were found among $>1500$ ovules examined $(n=23 \mathrm{FS})$. Eight of the 9 fruits were attached to a single flowering shoot, suggesting that pollen dispersal was a highly patchy and stochastic occurrence.

As with pollen dispersal, seed recruitment appeared to be a localized process with some dispersal over longer distances, similar to what was found for Phyllospadix torreyi elsewhere in Santa Barbara County (Reed et al. 2009), as well as for the congeners P. serrulatus and P. scouleri (Shelton 2008). Taking into account the effect of elevation, the variable relationship between seed production and recruitment may be due to the timing of the seed recruitment study (February 2008) or additional seed transport from neighboring areas. Our seed recruitment data are measured as the density of successful recruits, or attached seedlings, at each site. The potential mortality that occurred between fruit release (fall 2007) and attachment was not quantified, but may have affected the seed production-recruitment relationship observed here. Surf- grass seeds suffer high rates of mortality due to dislodgement from host plants, burial, desiccation (Turner 1983), and grazing (Holbrook et al. 2000). Seed mortality rates are lower where recruitment occurs under a surfgrass canopy (Shelton 2010c), and are likely higher at sites where recruitment predominantly occurred within the high elevation zone. A net onshore transport of seeds was identified, with seed recruitment greatest in the high elevation zone and lowest in the low zone. Recruitment to this exposed zone increased the likelihood of seed desiccation and dislodgement by winter storms.

Seed germination across the study sites was high and began following approximately 1 wk dormancy, shorter than that observed by Reed et al. (2009). The common-garden experiment was stopped $32 \mathrm{~d}$ after outplanting, and at this time the rate of germination was greatly reduced but had not reached 0 . Had the trial been extended, some additional germination may have occurred. Germination of the seeds reached 74 to $88 \%$ by Day 32, similar to previous studies (72 to $81 \%$; Reed et al. 1998). No seedling mortality was observed during the study period. Seed viability and early-stage seedling vigor were not affected by differences in male density or sex ratio, and thus environments with varied pollen production appear to sire seeds of similar quality (but not quantity).

In summary, we found sites with strongly skewed populations with female-biased sex ratios and 1 site composed exclusively of females, similar to other studies (Cox et al. 1992, Williams 1995, Shelton 2008, 2010b,c). At a few sites, males and females occurred in equal or nearly equal proportions. The density of male flowering shoots and degree of sex ratio bias appears to directly affect reproductive success at a site. Our results indicated that reproduction and recruitment of the surfgrass Phyllospadix torreyi occur on a scale generally localized to the parental source (10s of meters). Seed production was highly dependent on the local pollen production $(\leq 50 \mathrm{~m})$, quantified by sex ratio and male flowering shoot density. Seed recruitment was predicted by local (site) seed production and elevation zone. The occurrence of seed production and recruitment at sites with extreme male rarity suggests some dispersal of seed and pollen extending beyond the immediate vicinity of the site. Even incidental events of dispersal over longer distances may have influential effects by facilitating gene flow between populations and colonizing newly available habitat. 
Acknowledgements. This research was funded by the Interdepartmental Graduate Program in Marine Science (IGPMS) at the University of California, Santa Barbara, and the National Oceanic and Atmospheric Administration (NOAA), National Ocean Service, Center for Coastal Fisheries and Habitat Research. We thank J. Buckel for assistance with the manuscript and the many PISCO students and other volunteers who worked long, sleepless nights assisting with field surveys, particularly J. A. Macfarland, L. Dally, L. Herrera, and E. Pagaling. This is PISCO publication number 404.

\section{LITERATURE CITED}

Ackerman JD (1993) Pollen germination and pollen tube growth in the marine angiosperm, Zostera marina L. Aquat Bot 46:189-202

Ackerman JD (2000) Abiotic pollen and pollination: ecological, functional, and evolutionary perspectives. Plant Syst Evol 222:167-185

> Ackerman JD (2002) Diffusivity in a marine macrophyte canopy: implications for submarine pollination and dispersal. Am J Bot 89:1119-1127

Ackerman JD (2006) Sexual reproduction of seagrasses: pollination in the marine context. In: Larkum AWD, Orth RJ, Duarte CM (eds) Seagrasses: biology, ecology and conservation. Springer, Dordrecht, p 89-109

Addison CM (2009) When a male is hard to find: flower distributions and effects of male rarity in an intertidal seagrass community. MS thesis, University of California, Santa Barbara, CA

> Aguilar R, Galetto L (2004) Effects of forest fragmentation on male and female reproductive success in Cestrum parqui (Solanaceae). Oecologia 138:513-520

Aizen MA, Harder LD (2007) Expanding the limits of the pollen-limitation concept: effects of pollen quantity and quality. Ecology 88:271-281

Ashman TL, Knight TM, Steets JA, Amarasekare P and others (2004) Pollen limitation of plant reproduction: ecological and evolutionary causes and consequences. Ecology 85:2408-2421

Blanchette CA, Worcester SE, Reed D, Holbrook SJ (1999) Algal morphology, flow, and spatially variable recruitment of surfgrass Phyllospadix torreyi. Mar Ecol Prog Ser 184:119-128

Burd M (1994) Bateman's principle and plant reproduction the role of pollen limitation in fruit and seed set. Bot Rev 60:83-139

Burd M (1995) Ovule packaging in stochastic pollination and fertilization environments. Evolution 49:100-109

Burd M (2008) The Haig-Westoby model revisited. Am Nat 171:400-404

Campbell DR, Halama KJ (1993) Resource and pollen limitations to lifetime seed production in a natural plant population. Ecology 74:1043-1051

Cascante A, Quesada M, Lobo JJ, Fuchs EA (2002) Effects of dry tropical forest fragmentation on the reproductive success and genetic structure of the tree Samanea saman. Conserv Biol 16:137-147

> Cox PA, Tomlinson PB, Nieznanski K (1992) Hydrophilous pollination and reproductive morphology in the seagrass Phyllospadix scouleri (Zosteraceae). Plant Syst Evol 180: 65-75

> Davis HG, Taylor CM, Civille JC, Strong DR (2004) An Allee effect at the front of a plant invasion: Spartina in a Pacific estuary. J Ecol 92:321-327

den Hartog C (1970) The sea-grasses of the world. NorthHolland Publishing, Amsterdam

Fisher RA (1930) The genetical theory of natural selection. Oxford University Press, Oxford

Fonseca MS, Fisher JS, Zieman JC, Thayer GW (1982) Influence of the seagrass Zostera marina L. on current flow. Estuar Coast Shelf Sci 15:351-358

> Frank SA (1989) The evolutionary dynamics of cytoplasmic male-sterility. Am Nat 133:345-376

> Gaylord B, Reed DC, Raimondi PT, Washburn L (2006) Macroalgal spore dispersal in coastal environments: mechanistic insights revealed by theory and experiment. Ecol Monogr 76:481-502

Hamilton WD (1967) Extraordinary sex ratios. Science 156: $477-488$

Harder LD, Barrett SCH (1996) Pollen dispersal and mating patterns in animal-pollinated plants. In: Lloyd DG, Barrett $\mathrm{SCH}$ (eds) Floral biology: studies on floral evolution in animal-pollinated plants. Chapman and Hall, New York, NY, p 140-190

> Holbrook SJ, Reed DC, Hansen K, Blanchette CA (2000) Spatial and temporal patterns of predation on seeds of the surfgrass Phyllospadix torreyi. Mar Biol 136:739-747

Knight TM, Steets JA, Vamosi JC, Mazer SJ and others (2005) Pollen limitation of plant reproduction: pattern and process. Annu Rev Ecol Syst 36:467-497

Knight TM, Steets JA, Ashman TL (2006) A quantitative synthesis of pollen supplementation experiments highlights the contribution of resource reallocation to estimates of pollen limitation. Am J Bot 93:271-277

Kuo J, Iizumi H, Nilsen BE, Aioi K (1990) Fruit anatomy, seed germination and seedling development in the Japanese seagrass Phyllospadix (Zosteraceae). Aquat Bot 37:229-245

Larson BMH, Barrett SCH (2000) A comparative analysis of pollen limitation in flowering plants. Biol J Linn Soc Lond 69:503-520

- Lee TD, Bazzaz FA (1982) Regulation of fruit and seed production in an annual legume, Cassia fasciculata. Ecology 63:1363-1373

Maynard Smith J (1978) The evolution of sex. Cambridge University Press, Cambridge

$>$ Okubo A, Levin SA (1989) A theoretical framework for data analysis of wind dispersal of seeds and pollen. Ecology 70:329-338

> Pettitt J, Ducker S, Knox B (1981) Submarine pollination. Sci Am 244:134-143

Phillips RC (1979) Ecological notes on Phyllospadix (Potamogetonaceae) in the Northeast Pacific. Aquat Bot 6: 159-170

> Post E, Levin SA, Iwasa Y, Stenseth NC (2001) Reproductive asynchrony increases with environmental disturbance. Evolution 55:830-834

R Development Core Team (2011) R: a language and environment for statistical computing. R Foundation for Statistical Computing, Vienna. Available at www.Rproject.org

> Reed DC, Holbrook SJ, Solomon E, Anghera M (1998) Studies on germination and root development in the surfgrass Phyllospadix torreyi: implications for habitat restoration. Aquat Bot 62:71-80

Reed DC, Holbrook SJ, Blanchette CA (2009) Patterns and sources of variation in flowering, seed supply, and 
seedling recruitment in surfgrass Phyllospadix torreyi. Mar Ecol Prog Ser 173:13-23

Reusch TBH (2000) Pollination in the marine realm: microsatellites reveal high outcrossing rates and multiple paternity in eelgrass Zostera marina. Heredity 85: 459-464

Reusch TBH (2003) Floral neighbourhoods in the sea: how floral density, opportunity for outcrossing and population fragmentation affect seed set in Zostera marina. J Ecol 91:610-615

Rice WR (1989) Analyzing tables of statistical tests. Evolution 43:223-225

Ruckelshaus MH (1996) Estimation of genetic neighborhood parameters from pollen and seed dispersal in the marine angiosperm Zostera marina L. Evolution 50:856-864

Shelton AO (2008) Skewed sex ratios, pollen limitation, and reproductive failure in the dioecious seagrass Phyllospadix. Ecology 89:3020-3029

Shelton AO (2010a) Temperature and community consequences of the loss of foundation species: surfgrass (Phyllospadix spp., Hooker) in tidepools. J Exp Mar Biol Ecol 391:35-42

Shelton AO (2010b) The ecological and evolutionary drivers of female-biased sex ratios: two-sex models of perennial seagrasses. Am Nat 175:302-315

Shelton AO (2010c) The origin of female-biased sex ratios in intertidal seagrasses (Phyllospadix spp.). Ecology 91: 1380-1390

Stephenson AG (1992) The regulation of maternal investment in plants. In: Marshall C, Grace J (eds) Fruit and seed production: aspects of development, environmental physiology and ecology. Cambridge University Press, Cambridge, p 151-172

Steven JC, Waller DM (2007) Isolation affects reproductive success in low-density but not high-density populations

Editorial responsibility: Kenneth Heck,

Dauphin Island, Alabama, USA of two wind-pollinated Thalictrum species. Plant Ecol 190:131-141

Stewart JG, Rudenberg L (1980) Microsporocyte growth and meiosis in Phyllospadix torreyi, a marine monocotyledon. Am J Bot 67:949-954

Turner T (1983) Facilitation as a successional mechanism in a rocky intertidal community. Am Nat 121:729-738

- Van Tussenbroek BI, Montero MM, Wong R, Santos MGB, Guzman JM (2010) Pollen limitation in a dioecious seagrass: evidence from a field experiment. Mar Ecol Prog Ser 419:283-288

> Verduin JJ, Backhaus JO (2000) Dynamics of plant-flow interactions for the seagrass Amphibolis antarctica: field observations and model simulations. Estuar Coast Shelf Sci 50:185-204

Verduin JJ, Walker DI, Kuo J (1996) In situ submarine pollination in the seagrass Amphibolis antarctica: research notes. Mar Ecol Prog Ser 133:307-309

Waycott M, Procaccini G, Les DH, Reusch TBH (2006) Seagrass evolution, ecology and conservation: a genetic perspective. In: Larkum AWD, Orth RJ, Duarte CM (eds) Seagrasses: biology, ecology and conservation. Springer, Dordrecht, p 25-50

Werren JH, Beukeboom LW (1998) Sex determination, sex ratios, and genetic conflict. Annu Rev Ecol Syst 29: 233-261

> Wilcock C, Neiland R (2002) Pollination failure in plants: why it happens and when it matters. Trends Plant Sci 7 : 270-277

> Williams SL (1995) Surfgrass (Phyllospadix torreyi) reproduction-reproductive phenology, resource-allocation, and male rarity. Ecology 76:1953-1970

> Zimmerman M, Pyke GH (1988) Reproduction in Polemonium: assessing the factors limiting seed set. Am Nat 131: 723-738

Submitted: April 29, 2011; Accepted: December 26, 2011 Proofs received from author(s): March 2, 2012 